\title{
Case study - a high strength paste aggregate backfill at Randgold's Loulo mine in Mali
}

\author{
C Lee Golder Associates Ltd., Canada \\ P Gillot Randgold Resources Ltd, South Africa
}

\begin{abstract}
The Loulo mine complex in Mali is composed of a number of open pits and underground mines which extract a cyanide leachable gold ore. Two of the mines within the complex (Yalea and Gara mines) have nearly exhausted their pit resource and are transitioning to underground mining. The mining method chosen is sublevel open stoping (SLOS) with cemented and uncemented backfill. A large portion of the SLOS stopes will be relatively wide (up to $15 \mathrm{~m}$ ) and many of the stopes will be mined underhand with remote mucking under fill. To meet these requirements a high strength backfill is required which can reach strengths of $2.3 \mathrm{MPa}$ and can be delivered underground at adequate flow rates to satisfy the mines' cycle times.

This paper addresses the design of the paste backfill plants that are currently being constructed at the Yalea and Gara sites and will be operational in early 2014. The paste plants incorporate a number of interesting features to meet each mine's particular requirements while maximising the net present value (NPV) of the project. Specifically, the paper will illustrate a number of practical solutions to the challenges posed by tailings which exhibit poor strengths and poor dewatering properties. The solutions have resulted in a significant reduction in cement, and a projected yearly savings of over USD $20 \mathrm{~m}$ in cement costs.

In addition, the paper describes the decoupling processes and the resulting flexibility that decoupling imparts on the paste fill operations. The remoteness of the site and the lack of mining support infrastructure nearby was a concern for Randgold and therefore the system was designed so that key processes were decoupled such that the system could still function for significant periods of time, even when major elements of the system were shutdown (such as tailings supply from the mill).
\end{abstract}

\section{Introduction}

The Loulo mine in Mali consists of a number of open pit and underground mines located in close proximity to each other. The ore is processed in a central milling facility which uses a cyanide leach extraction. Tailings are pumped as a dilute slurry at $40 \%$ solids to a conventional tailings disposal facility.

Two of the mines, Gara and Yalea are located approximately 2 and $5 \mathrm{~km}$ respectively, away from the mill. Both mines consist of open pits approximately $1.5-2 \mathrm{~km}$ long. The orezone varies in thickness and dip however the average thickness is approximately $20 \mathrm{~m}$ and the average dip is approximately $70^{\circ}$. Both mines have extracted most of the open pit resource at the time of writing this paper and have started a substantial amount of underground mining to replace the tonnage from the pits as the pits reach their limit.

The ore reporting to the central mill is a variable combination of weak oxides (generally closer to surface) and harder, unoxidised ore at greater depths. The transition between the oxides and hard rock is variable; however, the transition to hard rock has mostly occurred at the time of writing this paper.

The mining method chosen for both Gara and Yalea is longitudinal and transverse sublevel open stoping (SLOS). Due to development schedule restrictions, the SLOS stopes will be underhand stopes with remote mucking. Nominal maximum widths of the stopes will be $15 \mathrm{~m}$. Initial backfill strength design calculations performed by Middindi Consulting (Pty) Ltd indicated a required strength of $2.3 \mathrm{MPa}$ for the underhand stopes which was used as the design criteria for the maximum required backfill strength. 
Both mines produce at a rate of $140,000 \mathrm{t}$ of ore per month which results in $50,000 \mathrm{~m}^{3} / \mathrm{month}$ of voids which must be mostly filled with cemented backfill (uncemented waste rock can be used in only a few isolated stopes).

\section{$2 \quad$ Backfill method selection}

In April of 2011, Randgold Resources Ltd (Randgold) commissioned Golder Associates Ltd. (Golder) to undertake a conceptual options evaluation to determine the optimum backfill method. An initial screening of seven options was performed; then three preferred options were taken forward to the conceptual design phase for evaluation based on technical and economic criteria.

The seven options are presented in Table 1.

Some of the primary framing behind the selection of the options for initial screening and the final selection of option $2 b$ - paste aggregate fill (PAF) with deslimed tailings are as follows:

- Cemented hydraulic fill (CHF) was not desired by the mine and was not included in the options evaluation. Both Randgold's and Golder's experience with cement laden decant water, zones of weakness in the fill due to wash out, and the high binder content required to reach the target strength of 2.3 MPa removed CHF from the options evaluation.

- Paste fill (PF) composed solely of unmodified tailings was not considered a viable option because of the following:

- The poor filtration characteristics of the unmodified tailings which would result in an abnormally large number of filters (and therefore higher capital and operating cost).

- The high cement content required to meet the target strength of $2.3 \mathrm{MPa}$ (and therefore, much higher operating costs).

- PF composed of deslimed tailings was also not considered a viable option even though the removal of some fine tailings material improved both the filtration rates and the strength of the paste; the cement content required to reach $2.3 \mathrm{MPa}$ was still exorbitantly high and resulted in an excessively high operating cost. Figure 1 shows the difference in strength between unmodified $100 \%$ tailings paste, deslimed $100 \%$ tailings paste and a $50: 50$ blend of deslimed tailings and aggregate. At $12 \%$ cement the unmodified $100 \%$ tailings recipe did not reach the $2.3 \mathrm{MPa}$ target at 28 days curing time and an even greater amount of cement would be required to reach the target.

- Cemented rockfill (CRF) was not considered a viable option because the placement of fill into the stopes could only be performed via back tipping underground haul trucks from the top sill level. This deposition method results in the coarse fraction of the CRF rolling down the rill angle and collecting at the perimeter walls of the stope while the fine, cement slurry portion collects near the discharge point. The segregation in CRF is well documented and is a significant concern for a mining method which relies on high strength homogenous fill with a target strength of $2.3 \mathrm{MPa}$ throughout. 
Table 1 Conceptual design options

\begin{tabular}{|c|c|c|c|c|c|c|c|}
\hline Option & Technology & $\begin{array}{l}\text { Percentage } \\
\text { tailings }\end{array}$ & $\begin{array}{c}\text { Percentage } \\
\text { aggregate }\end{array}$ & $\begin{array}{l}\text { Fill } \\
\text { transport } \\
\text { method }\end{array}$ & $\begin{array}{l}\text { Comparative } \\
\text { binder } \\
\text { consumption }\end{array}$ & Likeliness of being viable & Status \\
\hline $1 \mathrm{~A}$ & $\begin{array}{l}\text { Paste fill using } \\
\text { whole tailings }\end{array}$ & 100 & None & Hydraulic & Very high & $\begin{array}{l}\text { Very unlikely. Whole tailings filtration rates are } \\
\text { very low and binder addition would be very } \\
\text { high for target backfill strength }\end{array}$ & $\begin{array}{l}\text { Option } \\
\text { discarded }\end{array}$ \\
\hline 1B & $\begin{array}{l}\text { Paste fill using } \\
\text { deslimed tailings }\end{array}$ & 100 & None & Hydraulic & Very high & $\begin{array}{l}\text { Very unlikely. Deslimed tailings filtration rates } \\
\text { are acceptable but binder addition would still } \\
\text { be very high for target backfill strength }\end{array}$ & $\begin{array}{l}\text { Option } \\
\text { discarded }\end{array}$ \\
\hline $2 \mathrm{~A}$ & $\begin{array}{l}\text { Paste aggregate fill } \\
\text { using whole } \\
\text { tailings }\end{array}$ & 50 & 50 & Hydraulic & High & $\begin{array}{l}\text { Very unlikely. Whole tailings filtration rates are } \\
\text { very low and binder addition would likely be } \\
\text { high for target backfill strength }\end{array}$ & $\begin{array}{l}\text { Option } \\
\text { discarded }\end{array}$ \\
\hline $2 B$ & $\begin{array}{l}\text { Paste aggregate fill } \\
\text { (deslimed tailings) }\end{array}$ & 50 & 50 & Hydraulic & Intermediate & $\begin{array}{l}\text { Likely viable. Deslimed tailings filtration rates } \\
\text { are expected to be reasonably good and } \\
\text { binder addition was reasonable for target } \\
\text { backfill strength }\end{array}$ & $\begin{array}{l}\text { Option retained } \\
\text { for further } \\
\text { analysis }\end{array}$ \\
\hline $3 A$ & $\begin{array}{l}\text { Paste rockfill using } \\
\text { deslimed tailings } \\
\text { (no voids) }\end{array}$ & 30 & 70 & Mechanical & Low & $\begin{array}{l}\text { Likely viable. Mechanical transport for } \\
\text { Underground distribution system (UDS) needs } \\
\text { to be assessed in detail because of greater } \\
\text { interference with mining operations }\end{array}$ & $\begin{array}{l}\text { Option retained } \\
\text { for further } \\
\text { analysis }\end{array}$ \\
\hline $3 B$ & $\begin{array}{l}\text { Paste rockfill using } \\
\text { deslimed tailings } \\
\text { (with voids) }\end{array}$ & 20 & 80 & Mechanical & Low & $\begin{array}{l}\text { Likely viable. Mechanical transport for UDS } \\
\text { needs to be assessed in detail because of } \\
\text { greater interference with mining operations }\end{array}$ & $\begin{array}{l}\text { Option retained } \\
\text { for further } \\
\text { analysis }\end{array}$ \\
\hline 4 & Cemented rockfill & None & 100 & Mechanical & Low & $\begin{array}{c}\text { Unlikely. Backfill segregates inside stope } \\
\text { during placement, generating areas of } \\
\text { unacceptably low fill strength }\end{array}$ & $\begin{array}{l}\text { Option } \\
\text { discarded }\end{array}$ \\
\hline
\end{tabular}



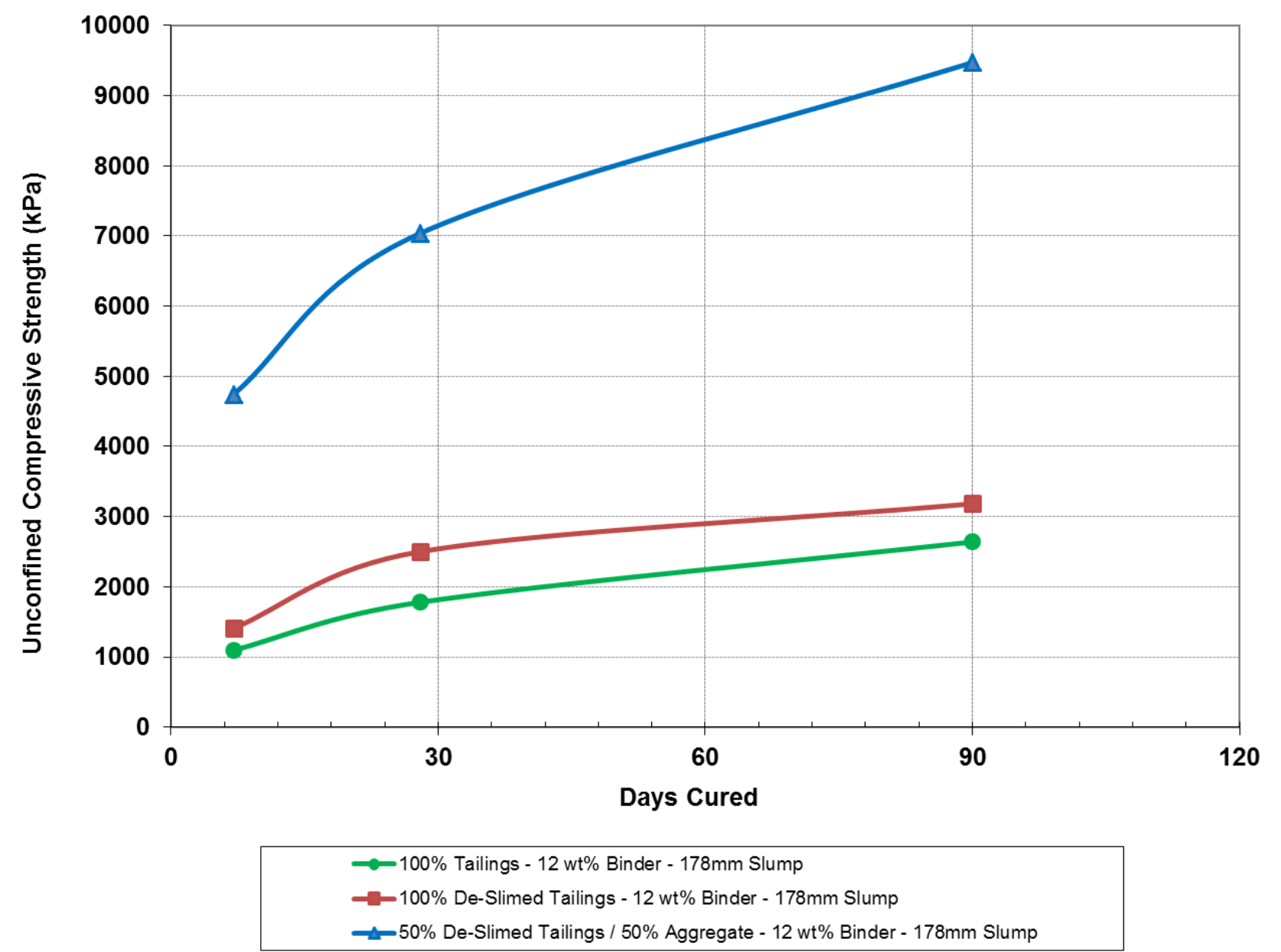

Figure 1 Tailings strength changes with the removal of fines and the addition of aggregate

Of the three options that were taken forward for further study, only the PAF using deslimed tailings was an option employing pipeline transport. The other two options (rocky paste fill (RPF) with 20\% fines and RPF with $30 \%$ fines) require truck transport of the fill from a waste pass drawpoint on each level. The increased amount of truck traffic on the levels due to backfill haulage was considered unacceptably high and the deslimed tailings PAF was selected as the preferred option.

Both the RPF options also presented the following disadvantages:

- There are a few mines which use RPF despite the fact that a number of mines have performed successful trials (Luke \& Rankine 2003) and (Kuganathan \& Sheppard 2001 ); however, the practice is not as common as other fill methods.

- Despite the fact that the RPF option included pre-mixing of the cement slurry, tailings, and rock so that the material was homogenous, it was expected that there would be some segregation of the coarse rock particles and fines matrix based on observations made at other mines. Because the Loulo backfill strength must be homogenous and of consistent quality to allow underhand mining, there was some concern that there would still be sufficient segregation to cause a problem with low strength 'dry zones' around the perimeter of the fill mass.

At the end of October 2011, the decision was made to proceed with the deslimed PAF method, and a detailed options evaluation phase was begun in order to finalise some of the outstanding issues raised during the scoping study. 


\section{Detailed options trade off for PAF}

At the end of the scoping study, the backfill method had been selected but some details regarding the backfill system required further examination, and decisions needed to be made prior to advancing the project to the detailed engineering stage. Some of the major decisions that were required are described below.

\subsection{Decoupling of the dewatering, crushing, and mixing circuits}

One of the major concerns was the remoteness of the site, access to skilled operations and maintenance personnel, and other factors that would make it more difficult to count on high availability rates for the backfill system. It was desired to decouple the mixing circuits from the crushing and dewatering circuits such that the plant could produce PAF even if the crushing system and/or the dewatering system was not available. This was accomplished by designing the system so that crushed rock could be fed into the mixing plant either directly from the crushing circuit or from a stockpile via a front end loader. Likewise the tailings filter cake could be fed into the mixing system directly from the disc filters or could be rehandled from a filter cake stockpile into the mixing system. Under most operating conditions with the crushing system and dewatering system operational, the crushed rock and tailings filter cake will be fed directly into the mixing system. However, if one of those subsystems is unavailable when it is desired to run the plant, PAF can still be produced by extracting material from the stockpiles. At any time during or after the PAF pour when the crushing or dewatering system has been brought back online, the crushed rock and tailings filter cake stockpiles could be replenished.

\subsection{The location of the dewatering plant}

Because the mill was located between the two mines, the option of having a central dewatering plant, that produced filter cake which would then be trucked to two remote mixing plants (one located at each mine site), was compared with pumping slurry to each mixing plant and performing the dewatering locally at each mixing plant. Although there is little technical difference between dewatering at the mill or the mixing plants, there was a significant NPV advantage for the dewatering at the mixing plants option. The advantage of dewatering at the mixing plants was mostly due to the lower operating cost of slurry pumping compared to truck transport of the filter cake.

\subsection{The location of the crushing plant}

Likewise with the crushing plant, it was investigated whether or not a single central crushing plant would be preferable or whether two smaller crushing plants at each of the mine would be preferable. The decision was made in much the same way as with the dewatering plant and included the following additional factors:

- The waste rock stockpiles are actually located at the mines and therefore there would be additional cost to truck the waste rock to the central crushing plant rather than extracting it via front end loader from the existing stockpiles immediately adjacent to the paste plant.

- An additional benefit of the two crushing plants is that if one crushing plant is down with a major problem and the crushed rock stockpile is exhausted, then crushed rock could be hauled from the other crushing plant to allow PAF to be produced.

\section{$3.4 \quad$ Thickening versus filtration}

Randgold expressed some interest in looking into the possibility of replacing the filtration circuit with deep tank thickening. However when the option was reviewed in detail, it became apparent that deep thickening was not the best solution for several reasons:

- The water balance (adding drier aggregate to a wetter thickener underflow) could not meet the $83 \%$ solids requirement for a $175 \mathrm{~mm}$ slump paste with $100 \%$ confidence. Although the water 
balance appeared to work out almost perfectly, (75\% solids thickener underflow mixed in a 50:50 ratio with $90 \%$ solids crushed rock yields an $82.5 \%$ resultant paste percentage solids), the water balance is so tight such that any upset in the thickening would result in an inability to meet the required percentage solids.

- The capital and operating cost savings would be minimal between a deep tank thickening system and a filtration system. Although the thickener itself is less expensive than the filters, the additional cost of a pipeline and pumps to deliver a high density, 'near paste' thickener underflow 2 and $5 \mathrm{~km}$ to Gara and Yalea mines respectively reduces much of that capital and operating cost savings.

- Since it is not practical to store a large amount of deep bed thickener underflow (i.e. it is not practical to store an amount of slurry that is equivalent to the $90 \mathrm{~h}$ surge available in the filter cake stockpile), the use of a deep bed thickener would make it impractical to decouple the dewatering system from the mixing plant.

- The tailings are expected to have some variability as the mines switch from surface oxide ore to deeper, unweathered ore. Tailings variability is more difficult to deal with in a deep bed thickener that is pushing the percentage solids to the limit. It has been Golder's experience that dealing with these fluctuations with some tailings materials has been challenging and has needed a solid understanding from the operators to keep the percentage solids (and underflow viscosity) near the target setpoint. Filtration is slightly more forgiving in that it does not require a lot of operator input.

\subsection{Central PAF plant at the mill}

Randgold was interested in a single PAF plant at the mill if possible. Golder conducted a study to determine what would be needed in order to satisfy that requirement. The main hurdle for the central plant option was the pumping requirement to reach the Yalea mine site. At $5 \mathrm{~km}$, the pumping costs for multiple booster stations and the requirement for cement retardants to address the long residence time in the pipeline made this option prohibitively expensive. This option was also fraught with technical challenges such as flushing over such a long distance and generally presented a greater risk to the mine than the alternatives.

\section{$4 \quad$ System design}

With the options evaluation completed, Golder proceeded to perform the backfill system design. Some of the highlights of the system design are presented in the next section. A simplified flow sheet of the system is shown in Figure 2.

\subsection{Cyclone system}

The cyclone system was designed to extract the majority of the smallest $20 \%$ size fraction from the tailings stream. With the reduction in the amount of slimes in the tailings, the filtration rate and UCS of the PAF were substantially improved (the improvement in filtration rates is shown in Figure 3 ). The cyclone system was designed by TWP Worley Parsons as part of a larger cyanide destruction and tailings handling system. The cyclone overflow is pumped to a clarifier prior to being sent to the tailings pond and the cyclone underflow is pumped overland to the mixing plants.

The cyclones are designed to remove only the finest fraction of the tailings stream (approximately $20 \%$ of the tailings reports to the overflow while the remainder reports to the underflow). This requires the use of numerous small cyclones (10 cm diameter first stage, $5 \mathrm{~cm}$ diameter second stage) rather than larger cyclones. In addition to removing the tailings fines, the cyclones dewater the tailings to $65 \%$ solids, which is an adequate solids content to feed the downstream vacuum filters. The added benefit of the cyclone system is that there is no requirement for any thickening of the tailings reporting to the paste plant. 


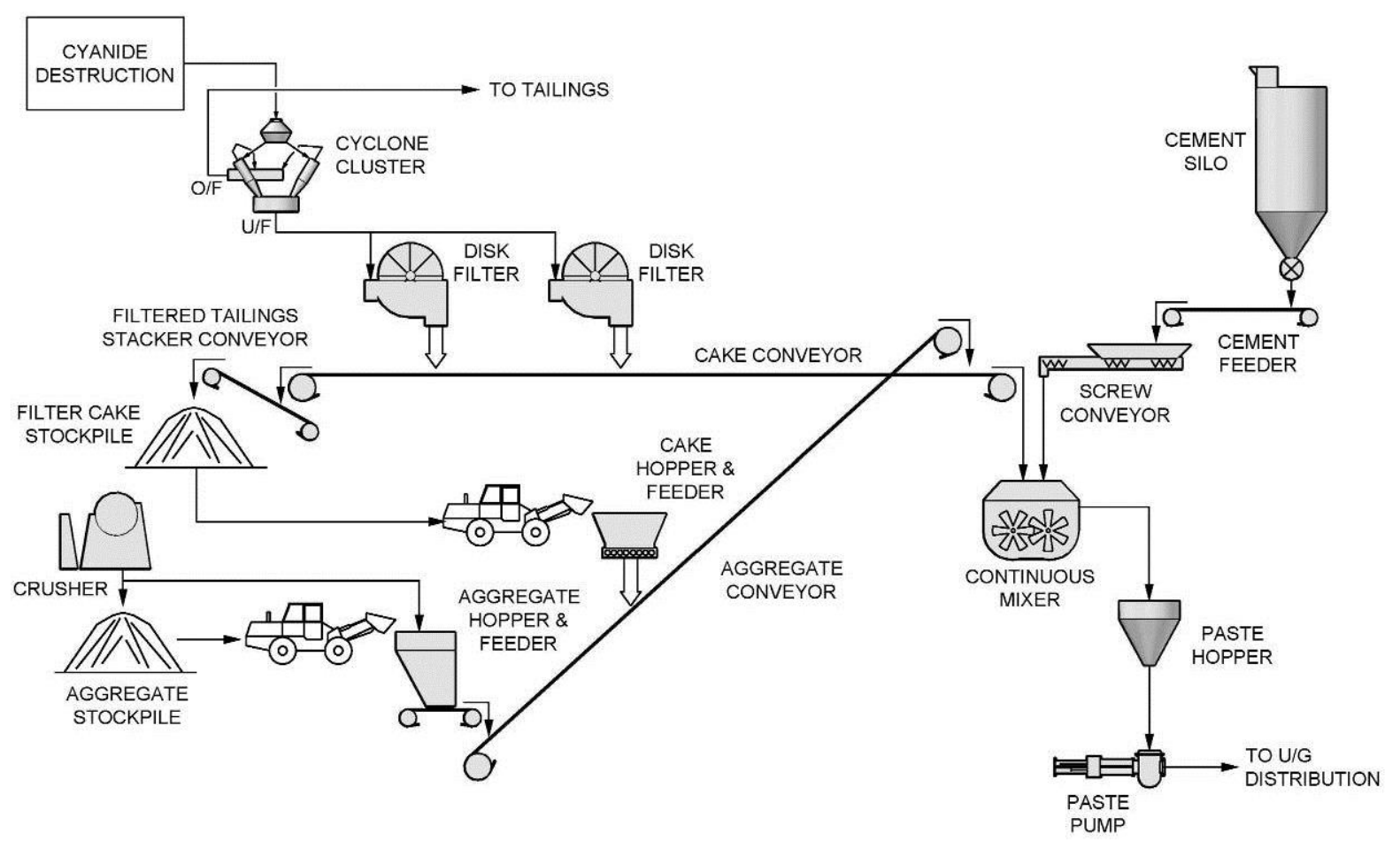

Figure 2 System design flow sheet

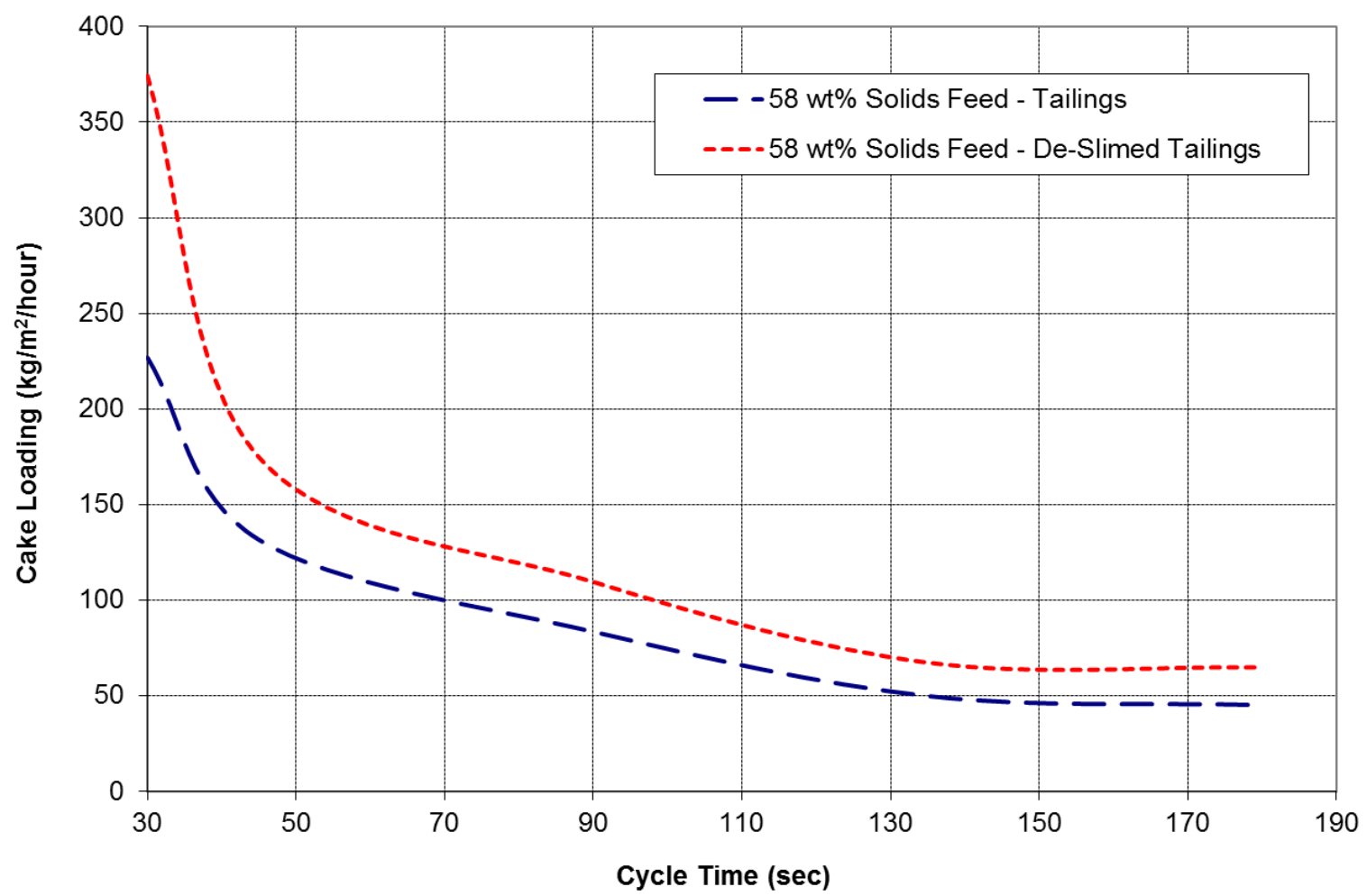

\section{Figure 3 Filtration rates}

\subsection{Aggregate and tailings load-in}

The aggregate produced by the aggregate plant (or from the aggregate stockpile) and the tailings produced by the filters (or from the stockpile) are brought into the mixing plant in a number of ways. Figure 4 shows the ramp arrangement which allows aggregate to be loaded in from one side and filter cake loaded in from the other side. The separation of the aggregate and filter cake stockpiles onto two sides of the ramp makes 
it less likely that the operators will accidentally dump aggregate into the filter cake hopper and vice versa (since the operator would have to travel completely around the plant with a full bucket to be able to do so).

The aggregate material was tested for its bin flow characteristics (potential for arching and ratholing, etc.). Under normal circumstances, the front end loader is not required to load aggregate into the aggregate surge bin since the crushing system delivers aggregate directly into the bin. The bin has 45 minutes of surge capacity. It is normally operated at three quarters full in order to have some surge capacity to continue running the PAF plant if the crushing system is temporarily unavailable and some surge capacity to accommodate an orderly shutdown of the crushing plant if the PAF plant requires a sudden stop.

The tailings load-in is via a live bottom feeder which has eight screw conveyors at the bottom of the hopper which convey the sticky tailings filter cake to a discharge location. The live bottom is required (rather than a typical bin and feeder conveyor interface) because the tailings material is prone to arching and designing a bin interface wide enough to prevent arching is considered to be impractical.

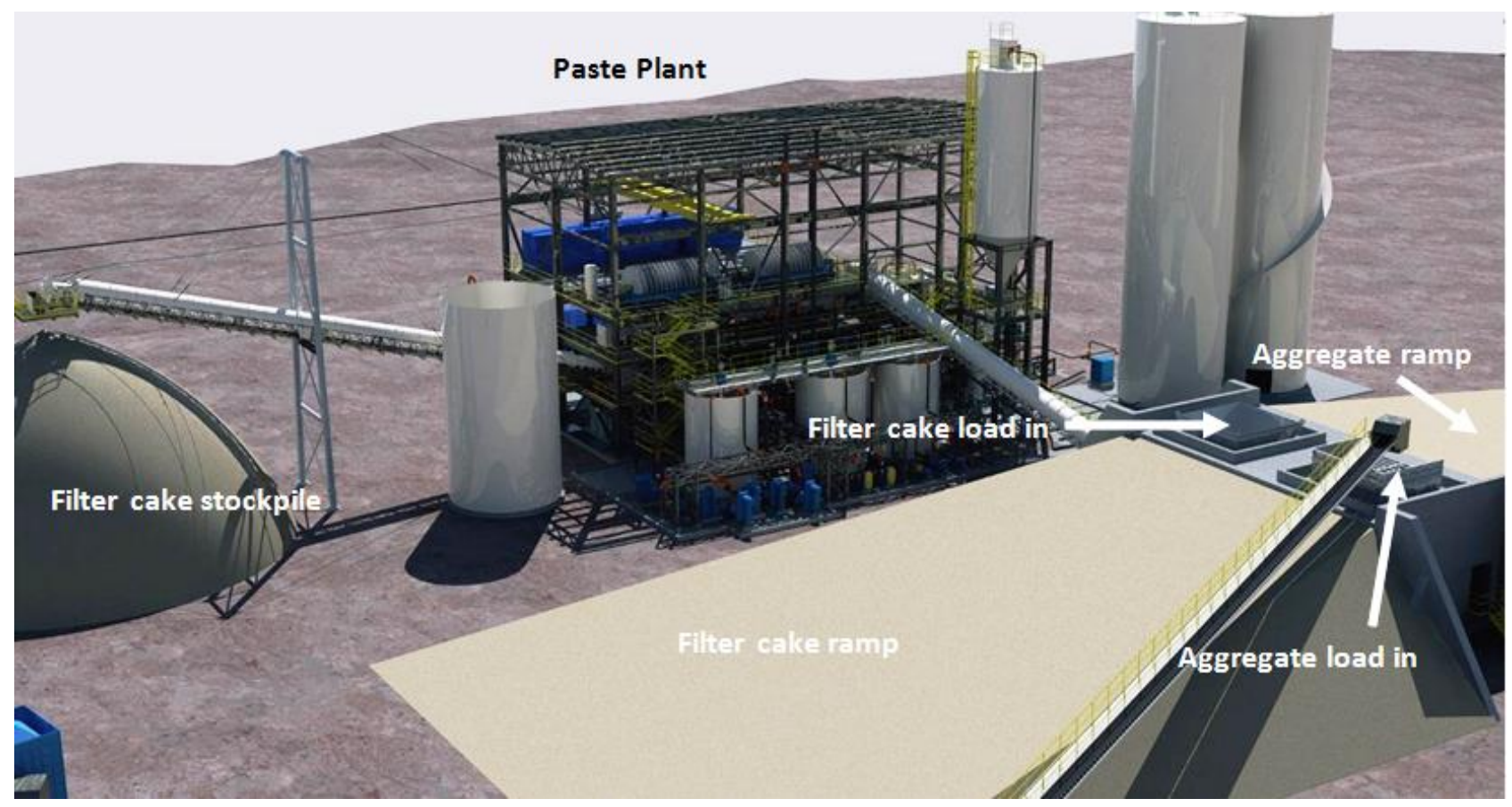

Figure 4 Ramp arrangement

Under normal circumstances load-in of tailings to the mixing system occurs directly from the vacuum filters to the mixer feed conveyor and the tailings never leave the plant and never require rehandling by front end loader.

\subsection{Cement delivery and storage}

The mine site is located at some distance from a major centre. There are cement plants within a reasonable distance to the mine site, however, the road conditions are sometimes very poor and supplies cannot be counted on to reach the mine site in a timely fashion. Because of this, the cement system was designed to accommodate the remote nature of the mine site as follows.

The cement will be delivered in isotainers, which are ISO container sized vessels that can be stacked and shipped in a similar way as any other ISO containers. The isotainers will be filled at the cement plant, then loaded onto flatbed trucks which will transport the isotainers to the mine site. In areas with easier access to large cement plants, the isotainers would not be needed since cement tankers would be used to transport the cement powder, however, the typical mode of transportation in Mali is by $1 \mathrm{t}$ bulk bag. Bulk bags would require a large storage and unloading system, as well as labour and maintenance on the extra equipment. By contrast, the isotainers are unloaded pneumatically in a sealed system with no dusting and no wastage 
of unused cement in bags that are not completely emptied. In addition, the isotainers do not need any roof cover or other protection to keep them safe from water ingress. The actual capital cost of the isotainers was also quite reasonable when compared to the cost of the bag unloading system and storage area, and at USD 13,000 per $20 \mathrm{t}$ isotainer, the total capital cost of the 55 containers was less than the cost of the bag unloading and storage system with none of the high operating costs. Similar isotainers to the ones purchased for Randgold are shown on Figure 5.

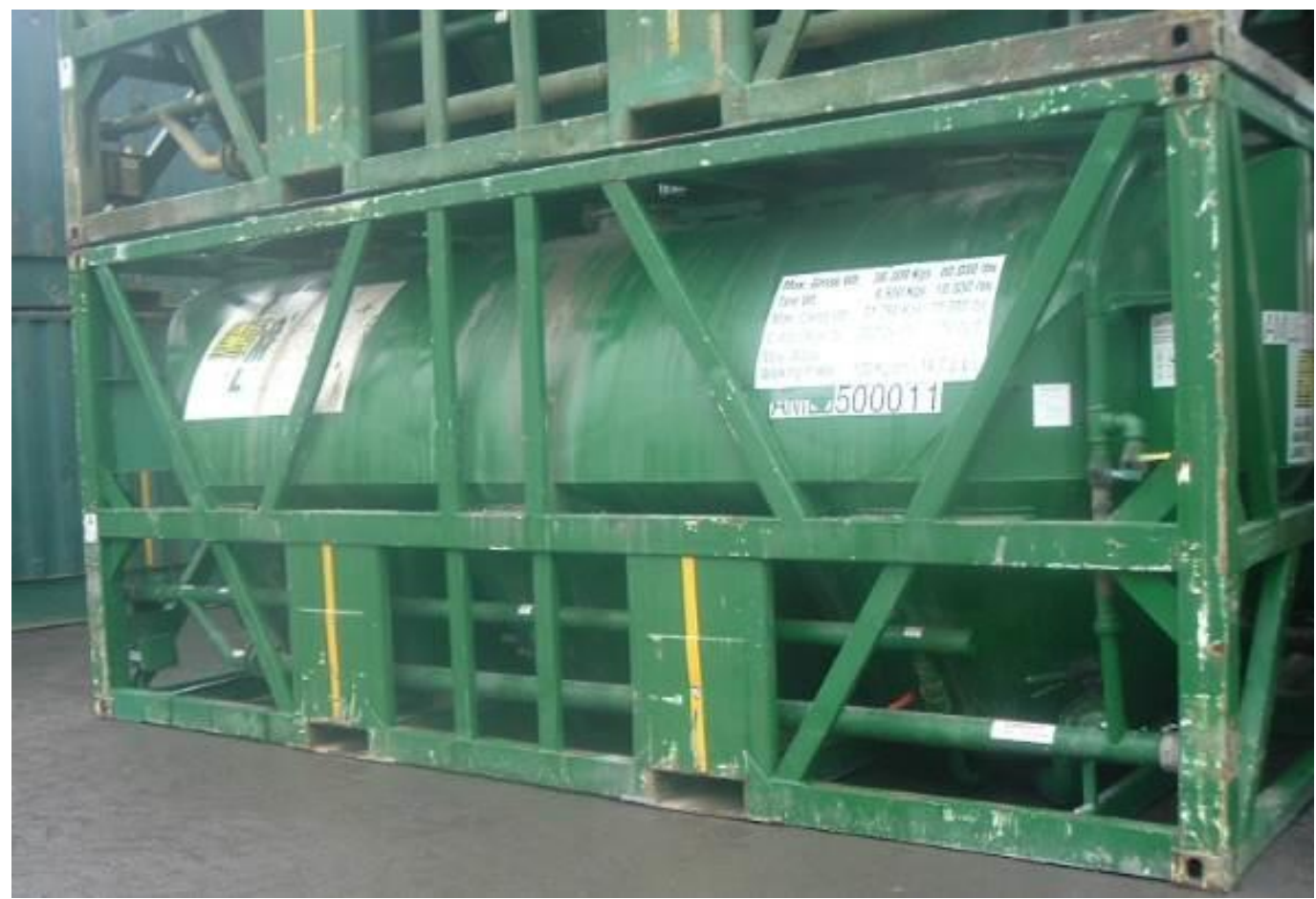

\section{Figure 5 Isotainers}

Cement will be offloaded into two 2,500 t silos (two at each plant). The large storage silos will provide 15 days of surge capacity and accommodate prolonged periods where no cement will reach the PAF plant. Cement from the storage silos will be transferred pneumatically to the day silo when required. The day silo will discharge onto a weigh feeder and hence, into the mixing system. Normally, cement will be offloaded directly from the isotainer to the day silo unless there is a delay in the delivery of cement from the factory (or if a certain amount of time has elapsed and it is desired to draw down the cement silo inventory to ensure that the cement does not age in the silo for an unacceptably long time).

\subsection{Paste mixing}

The paste mixing system consists of a twin shaft mixer that receives filter cake, aggregate, dilution slurry, cement, and dilution water before mixing the constituents to the desired relative viscosity as measured by the mixer motor power draw.

The mixer has been designed such that the discharge level (and therefore the fluid level in the mixer) is approximately mid-shaft rather than being higher than the shaft level. While it is relatively common to maximise the level in the mixer, Golder Associates Ltd. has taken the approach to oversize the mixer and have a lower paste level in the mixer which induces less hydraulic head on the grease purged shaft seals. One of the major maintenance headaches for paste backfill operations is the change-out of the mixer seals. By minimising the head on the seals, the amount of PAF entering the seals will be minimised. Golder has observed this effect in a number of its previous plants where high paste levels in the mixer will result in a more frequent seal change-out than a low paste level.

The discharge of the mixer is via twin overflow ports (one operating and one standby). A hinged chute and a hinged door allow the mixer to discharge to one side or the other (or, theoretically, both sides at the 
same time). The use of the dual discharge into individual hoppers above the operating and standby paste pump rather than discharging into a single paste hopper allows the plant to be approximately $3 \mathrm{~m}$ lower than would be required with a single hopper arrangement. In addition, it allows the hopper to be positioned directly over the paste pump with no piping restrictions from a central hopper which would reduce the filling efficiency of the pump during its suction strokes. The hopper mounted above the pump is also useful since it allows direct overhead crane access into the swing tube area of the pump rather than having the pump be inaccessible by the crane.

\subsection{Paste pumping}

The paste pumps are swing tube Putzmeister KOS 25100 with $800 \mathrm{~kW}$ power packs. The swing tube style pumps are required since the PAF contains up to $15 \mathrm{~mm}$ aggregate which is too large for poppet valve style pumps. Figure 6 shows the paste pumps in position.

It should be noted that the swing tube type of pump relies on the presence of a suitable gradation of coarse material in order to make the seal between the spectacle plate and the swing tube. This means that when selecting a swing tube pump there is no option of pumping $100 \%$ tailings paste for any significant time at any significant pressure. Without the coarse particles the fines will jet wear through the gap between the wearing surfaces and result in significant wear.

The discharge of the pump also incorporates a Putzmeister HMCS valve, which essentially isolates the pump from the discharge line at each stroke so that during the relatively slow switchover of the swing tube, the line does not depressurise back into the pump hopper.

\subsection{Underground distribution system}

Due to the high abrasion expected by the PAF, a highly abrasion resistant pipeline material was selected. All the main boreholes and trunk lines are API $5 \mathrm{~L}$ Gr. X52 Schedule 60 steel pipes with a $12 \mathrm{~mm}$ thick ceramic bead/resin lining. Main line piping is connected using Victaulic style 808 couplings. Borehole casing is connected using an external shoulder coupling that is rated only for the self-weight of the casing as it is installed in the borehole. The external shoulder coupling has no gasket and does not retain pressure, however, it is being used since welding of the ceramic lined casing is not possible without damaging the ceramic and this coupling allows quick and easy connection of the casing lengths prior to lowering and grouting the casing into the borehole. Once grouted, the grout will contain the pressure of the casing at the joints (rather than the coupling).

Boreholes are $325 \mathrm{~mm}$ raisebore pilot holes drilled at angles of $60-70^{\circ}$ (except for one borehole which was restricted by the mine layout such that it required a $47^{\circ}$ angle to reach its target). While it is not desirable to have such a shallow borehole, since it is on the borderline of not self-draining when full of paste, the other options such as drifting out over $100 \mathrm{~m}$ to meet a $60^{\circ}$ angle hole were less desirable.

Main boreholes are all installed with a secondary borehole as a backup. Mainline piping has no backup since it is accessible and can be cleaned if blocked. Since the paste plant is located in the relative centre of the orebody, and since the boreholes splay off towards either end of the orebody, half the mine will still be available for paste filling even when both the main borehole and the standby borehole in one direction is unavailable. 


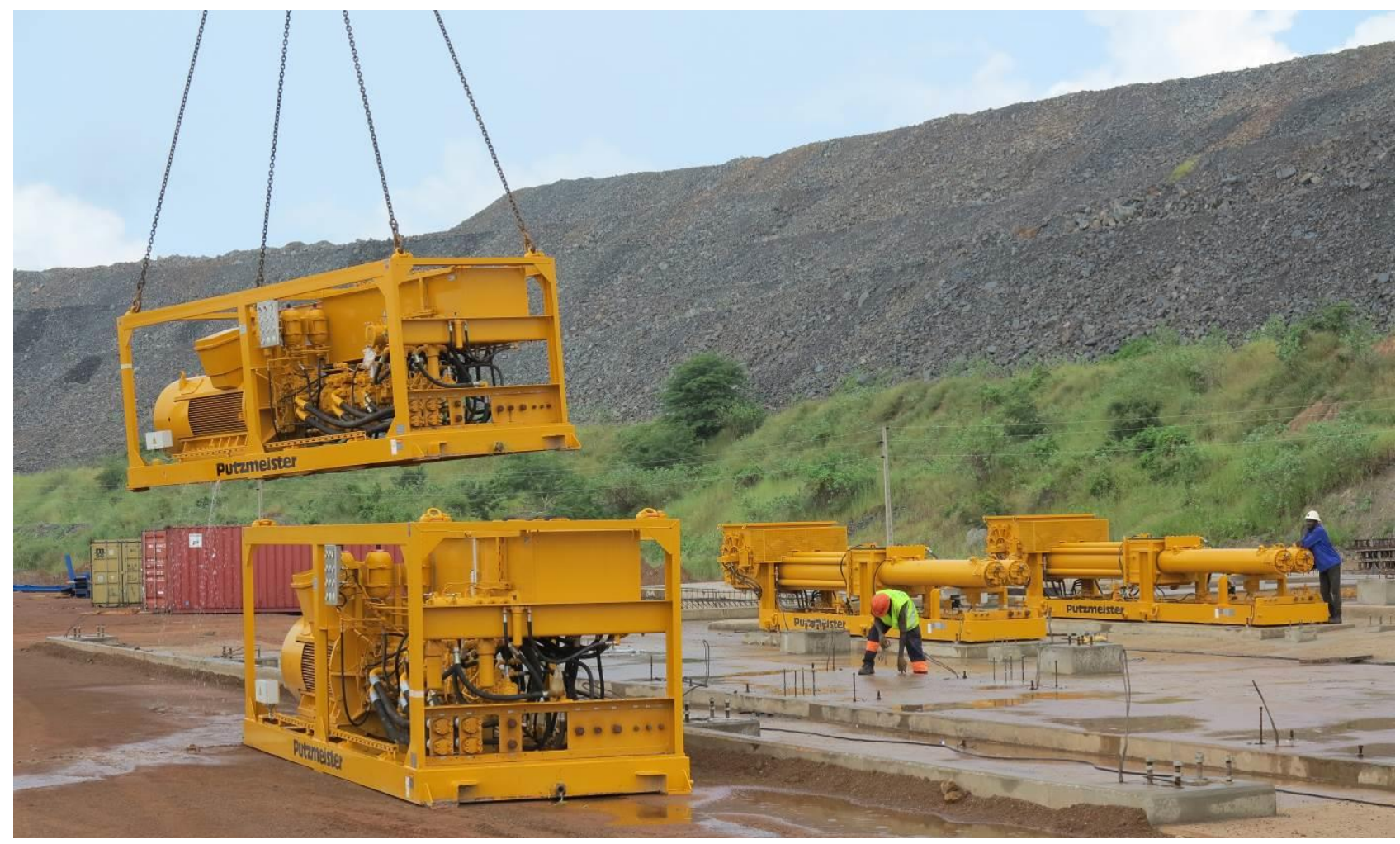

\section{Figure 6 Paste pumps positioning}

The specification of the ceramic lined pipe was one of the more interesting engineering evaluations during the project, since Golder was only familiar with one qualified supplier of ceramic lined piping who had experience with paste fill and even that experience was based on fine particle paste fills and not PAF. However, a number of other suppliers also put forward their products as viable contenders and illustrated their experience in similar industries such as bottom ash slurry transportation. In the end, Golder recommended a single supplier for the majority of the piping; however, Golder also recommended that Randgold purchase a nominal amount of piping from all suppliers and install the piping in a main trunk line portion of the UDS so that an evaluation could be made of the different piping wear resistance.

\section{$5 \quad$ Conclusion}

The paste plants being constructed at Randgold's Loulo mine include a number of innovative methods to achieve the relatively high strength requirements of $2.3 \mathrm{MPa}$ in a cost efficient and reliable manner. The key features of this case study are:

- Cyclone extraction of fines to improve filtration rates and strength, and to avoid the requirement for a thickener.

- Decoupling of the paste plants so that they can still function for several days even when the cycloning, dewatering, aggregate, or cement delivery components of the plant are not available.

- Addition of aggregate to improve strengths.

- Robust and cost effective cement delivery and storage system.

- Ceramic lined mainline piping and casing.

The paste plants will be commissioned in the early part of 2014, and the authors look forward to future assessments of the effectiveness of the engineering solutions to Randgold's challenging backfill requirements. 


\section{References}

Kuganathan, K \& Sheppard, I 2001, 'A non-segregating "rocky paste fill" (RPF) produced by co-disposal of cemented de-slimed tailings slurry and graded rockfill', in D Stone (ed.), Proceedings of the 7th International Symposium on Mining with Backfill, Society for Mining, Metallurgy, and Exploration, Englewood, pp. 27-41.

Luke, D \& Rankine, R 2003, 'Spatial variation in a paste-rock filled stope', Proceedings of the International Seminar on Paste Thickened Tailings, Australian Centre for Geomechanics, Perth, Section 21. 